Original Article

\title{
FOOD ADULTERATION AND FAMILY'S KNOWLEDGE ON FOOD ADULTERATION IN SELECTED VILLAGE OF UDUPI TALUK, KARNATAKA.
}

\author{
Abidfaheem T.K. ${ }^{1}$, Baby S. Nayak ${ }^{2} \&$ Maxie Andrade ${ }^{3}$ \\ ${ }^{1}$ Department of Community Health Nursing, ${ }^{2}$ Professor \& Head, Department of Child Health Nursing, \\ ${ }^{3}$ Assistant Professor, Department of Community Health Nursing, M anipal College of Nursing, \\ Manipal University, M anipal, Udupi - 576104 \\ Correspondence: \\ Abidfaheem T.K. \\ Department of Community Health Nursing, M anipal College of Nursing, Manipal University, \\ Manipal, Udupi - 576104 \\ M obile: +919809649910 E-mail : abidfaheemtri@gmail.com
}

\begin{abstract}
:
A cross sectional survey was under taken among 75 families using structured knowledge questionnaire and observation technique. The collected data was analysed using SPSS version 16 . The study findings showed that majority (60\%)of the subjects had moderate knowledge on food adulteration. Out of 75 samples tested, $2.7 \%$ chili powder samples were adulterated with artificial color and $10.7 \%$ of the common salt samples were adulterated with insoluble impurities. In tea powder $12 \%$ were adulterated with iron fillings and $2.7 \%$ were adulterated with artificial color. There was significant association of knowledge score on food adulteration with age $\left(\chi_{(2)}^{2}=8.627 \mathrm{p}=\right.$ 0.013 ) and educational status $\left(x_{(4)}^{2}=9.876, p=0.043\right)$ of the respondents. The study concludes that the food adulteration even though low, still it is existing. However awareness of the public in relation to food adulteration should be ongoing especially to the general public with lower level of education.
\end{abstract}

Keywords: Food adulteration, knowledge, family, detection, food items.

\section{Introduction:}

Food is the basic requirement of all living beings for their growth.It is the right of every citizen to have access to clean, safe and nutritious food. The health and the productivity of population depend on the nature of the food theyconsume and its wholesomeness in terms of their nutritive value. One works hard and earns to satisfy his/ her hunger. But at the end of the day, many of us are not sure of what we eat. We may be eating a dangerous dye, sawdust, soapstone, industrial starch, aluminum foil and so on! Contaminated foods and drinks are common sources of infection. Often, we invite Access this article online Quick Response Code

品和品
diseases rather than good health.It has become verydifficult for the items because of $\mathrm{m}$ i s l e a d i n g advertisements, improper consumer to select food mediaemphasis and food adulteration. As a result the ultimate victim is a consumer, whoinnocently takes adulterated food and suffers ${ }^{1}$.

Ensuring food safety has been recognized as an important component in protecting the health of the people. Public's best defense is knowledge of his or her rights as consumer and of the remedies which exists to resolve these problems when they occur. The purpose of this study was to assess knowledge on food adulteration and to detect food adulteration of selected food items with a view to prepare pamphlets which will further help to create awareness among family members on food adulteration and food adulteration detection methods, thereby reduce the risk caused by food adulteration. The objectives of the study were to assess the knowledge on food adulteration among families, detect food adulteration in selected food items, and to find the association between the knowledge with selected variables. 


\section{Materials and Methods:}

A descriptive cross sectional survey was carried out in select village of Udupi District. In this study one panchayat under field practice area attached to medical college was selected by convenient sampling. The selected panchayt consisted of 13 wards. Among these 13 wards, one ward was selected by using simple random sampling technique. The selected ward consists of 486 families. Sample size was calculated based on pilot study using the formula estimation of population mean by relative precision as $n=$ $Z^{2}(1-\alpha / 2) \sigma^{2} / ?^{2} \mu^{2}$ The $Z$ value is taken with $95 \%$ of confidence interval. As per the computation the needed sample for the study was 59, total 75 sample were included in the study considering the $10 \%$ non-response rate. Systematic random sampling was ado pted. Since the $\mathrm{K}^{\text {th }}$ number was 6 , every $6^{\text {th }}$ family was selected. The administrative permission for conducting the research study was obtained from concerned authorities. Written consent was taken from each of the participants who were willing to participate in the study, after ensuring the confidentiality. Total three tools were used for data collection; Tool I : Sample characteristics Tool II: Structured knowledge questionnaire on food adulteration. Tool III : Detection record. Knowledge of the family was assessed by administering structured validated, reliable $\left(r_{(d f)}=0.867_{(19)}\right)$ knowledge questionnaire which was administered to head of the family or wife of the head of the family and detection on food adulteration conducted in home setting by simple detection methods. The reliability of the testing methods was achieved by inter rater reliability with the food inspector of the district. Pilot study was conducted by administering the tools to 20 sample and sample calculation was done by using the formula estimation of population mean by relative precision. The data was collected in the month of January 2012. The questionnaire was administered to Head of family or wife of head of family after obtaining informed consent and ensuring confidentiality. After that specimens for detection were collected from each family and detection was done through simple detection methods in home set up in selected five food items. Based on the knowledge level of the sample a pamphlet was prepared and distributed.

\section{Statistical analysis:}

Statistical package for social sciences software (version 16) was used for statistical analysis of raw data. Frequency, percentage, mean, standard deviation and Chi-Square test (p0.05) were applied.

\section{Results :}

Sample characteristics and nature of buying and storing of food items are described in table 1 and 2 .

\section{Description of knowledge score :}

The maximum possible knowledge score was 24. M inimum score obtained by the sample was 4 and maximum score was 19. The mean score of the participants were 12.31 with S.D. of 3.897.Among 75 participants, 14 (18.7\%) had poor knowledge(0-8), 45 (60\%) had average knowledge (9-16) and 16 (21.3\%) had good knowledge(17-24) on food adulteration. The percentage distribution of sample based on knowledgescore isshown in the figure: 1

\section{Detection of food adulteration :}

Out of 75 samples, none of the turmeric powder samples were adulterated with metanil yellow, while $2(2.7 \%)$ chilli powder samples were adulterated with artificial color. The test revealed that $8(10.7 \%)$ of the common salt sample were adulterated with insoluble impurities. Out of 75 samples, $9(12 \%)$ samples of the tea powder were adulterated with iron fillings and $2(2.7 \%)$ were adulterated with artificial color. Out of 47 available coriander powder samples, none of them showed positive reaction to adulteration test.

\section{Association between knowledge score and demographic variables:}

The Association between knowledge score on food adulteration and demographic variables revealed that there was a statistically significant association between knowledge on food adulteration and age $\left(\chi_{(2)}^{2}=8.627, p=\right.$ 0.013 ) and interpreted that the people with $25-50$ years of age had better knowledge than people above 50 years of age. The statistically significant relationship was also found between knowledge on food adulteration and educational 
status $\left(\chi_{(4)}^{2}=9.876, p=0.043\right)$ and interpreted that sample who had PUC and above level of education had better knowledge. There was no statistically significant association found between knowledge on food adulteration and demographic variables such as gender $\left(\chi^{2}\right.$ $\left.{ }_{(2)}=2.601 p=0.272\right)$, occupation $\left(\chi_{(4)}^{2}=8.766, p=0.067\right)$ and monthly family income in rupees $\left(\chi_{12}^{2}=4.257, p=0.119\right)$.

The computed value of chi-square between knowledge score on food adulteration and variables on buying and storing of food items revealed that the knowledge scores on food adulteration were independent of place of purchase $\left(\chi_{(4)}^{2}=1.593, p=0.810\right)$, type of packing $\left(\chi_{(2)}^{2}=2.39\right.$, $p=0.664)$, average duration of storage of general grocery items $\left(\chi_{(2)}^{2}=1.647, p=0.439\right)$, average duration of storage of turmeric powder $\left(\chi_{(2)}^{2}=3.208, p=0.201\right)$, average duration of storage of common salt $\left(\chi_{(2)}^{2}=3.089, p=0.213\right)$, average duration of storage of chilli powder $\left(\chi_{(2)}^{2}=2.101, p=0.350\right)$, average duration of storage of tea powder $\left(\chi_{(2)}^{2}=1.085\right.$, $p=0.581$ ), and average duration of storage of coriander powder/coriander $\left(\chi_{(2)}^{2}=1.647, p=0.439\right)$.

\section{Discussion :}

The findings of the present study indicate that among 75 respondents $18.7 \%$ had poor knowledge, $60 \%$ had average knowledge and $21.3 \%$ had good knowledge on food adulteration. This finding is supported by a similar descriptive study conducted by Gupta Nidhi and Panchal Priti in 2007 among 60 families of Mahadev village of Gujarat state, $15 \%$ of the sample had low awareness, $60 \%$ had moderate awareness and $25 \%$ had high awareness on food adulteration. The maximum possible score was 33 . The mean score obtained by the participants was 23.15 with S.D of 2.77 . $^{1}$ The present study is also supported by another study conducted in 1999 on knowledge of consumers regarding the nature and extent of adulteration of Indian foods among 60 women of Hisar city in India, showed that majority, $61.6 \%$ of respondents had medium knowledge on food adulteration, $40.0 \%$ and $10.0 \%$ had high knowledge. ${ }^{5}$

The present study is supported by many studies conducted by Beniwal $A$ and Khetarpaul $\mathrm{N}^{5}$ among 60 women of Hisar city in India, who reported that sample of turmeric powder were found to be adulterated with chalk powder. Water soluble colour was also added to $36.6 \%$ of the samples, all samples of red chilli powder were adulterated with artificial colour, and oil-soluble coal tar dye was detected in 36.6 percent of them, while brick powder was present in 23.3 percent. Another Survey conducted by Mysore Grahakara Parishat ${ }^{3}$ in 2008 in Mysore, Karnataka also revealed Metanil yellow and lead chromate were the common adulterants found in food products. Out of four hundred samples collected from 38 local shops, 43 \%of toor dhal was found adulterated. $50 \%$ of Bengal gram was of poor quality, $28 \%$ samples had Metanil yellow, $6 \%$ had auramine dye and $29 \%$ of green gram was adulterated. Other samples such as turmeric, chilli powder, cumin seeds, ghee and butter were also highly adulterated.

The present study revealed that there was association between knowledge on food adulteration and age $\left(\chi^{2}\right.$ $=8.627, p=0.013)$. The study also revealed that there was association between knowledge on food adulteration and educational status $\left(\chi_{(4)}^{2}=9.876, p=0.043\right)$. The findings are supported by other studies available in the literature ${ }^{1}$ Anotherstudy was conducted by Bhatt, and Anita Singh on impact analysis of knowledge and practice for food Safety. Study revealed that age and awareness were not interlinked which is contradictory to the present study finding, while education was interlinked with good practices which supporting the findings of present study ${ }^{6}$.

\section{Conclusion:}

The prevalence of adulteration among selected food items even though is low, adulteration is existing in village. The present study found $60 \%$ of the sample population had average knowledge on food adulteration. Awareness of the public in relation to food adulteration should be ongoing especially to the general public with lower level of education.

\section{Limitations:}

The detection of adulteration is limited to five specific food items and knowledge is assessed only from head of the 
family or wife of the head of the family.

\section{Acknowledgment :}

We express our sincere thanks to Dr. Anice George, Dean M CON M anipal and Dr. Veenakamath, HOD, Department of
Community Medicine, Kasturba M edical College, Manipal University, M anipal for giving administrative permission to conduct the study. We express my sincere thanks to $\mathrm{Mr}$. Chandrakanda M anjerekar, Food Inspector, Udupi District, for his support and guidance throughout the study.

Table 1: Description of demographic variables $(n=75)$

\begin{tabular}{|c|l|c|c|}
\hline SI. No. & Sample characteristics & frequency & Percentage(\%) \\
\hline 1. & Age in years & & \\
\hline & 25 to 50 & 44 & 58.7 \\
\hline & 51 to 75 & 31 & 41.3 \\
\hline 2. & Gender & 34 & 45.3 \\
\hline & Male & 41 & 54.7 \\
\hline & Female & 39 & 52.0 \\
\hline 3. & Education & 20 & 26.7 \\
\hline & SSLC and below & 16 & 21.3 \\
\hline & PUC & & \\
\hline & Diploma, graduate & & \\
\hline 4. & Occupation above & 21 & 28.0 \\
\hline & Coolie & 26 & 34.7 \\
\hline & House wife & 28 & 38.3 \\
\hline & Government / private job & 25 & 33.3 \\
\hline 5. & Monthly family income in Rupees & 66.7 \\
\hline & Less than 6000 & 50 & \\
\hline & 6000 and above & \\
\hline
\end{tabular}

Table 2: Description of variables related to food items

$(n=75)$

\begin{tabular}{|c|c|c|c|}
\hline Sl. No. & Sample characteristics & frequency & Percentage(\%) \\
\hline 1. & \multicolumn{2}{|l|}{ Place of purchase of food items } & \\
\hline & Local shop & 34 & 45.3 \\
\hline & Branded shop & 11 & 14.7 \\
\hline & Both & 30 & 40.0 \\
\hline \multirow[t]{4}{*}{2.} & Type of packing of food items & & \\
\hline & Loose & 30 & 40.0 \\
\hline & Packed & 14 & 18.7 \\
\hline & Both & 31 & 41.3 \\
\hline \multirow[t]{3}{*}{3.} & \multicolumn{2}{|c|}{$\begin{array}{l}\text { Average duration of storage of general } \\
\text { Grocery items after purchasing }\end{array}$} & \\
\hline & Less than 1 month & 32 & 42.7 \\
\hline & 1 month and more & 43 & 57.3 \\
\hline \multirow[t]{3}{*}{4.} & Buying member of the family & & \\
\hline & Head of the family & 36 & 48.0 \\
\hline & Wife of Head of the family & 39 & 52.0 \\
\hline
\end{tabular}


Table 3: Association between knowledge score on food adulteration and demographic variables.

\begin{tabular}{|c|c|c|c|c|c|}
\hline Sample Characteristics & \multicolumn{7}{|c|}{ Knowledge Category } & $\chi^{2}$ (df) & P value \\
\hline \multicolumn{7}{|c|}{ Poor f(\%) } & Average f(\%) & Good f(\%) & \\
\hline Age in years & $4(9.1)$ & $27(61.4)$ & $13(29.5)$ & $8.627(2)$ & $0.013^{*}$ \\
\hline $25-50$ & $10(32.3)$ & $18(58.1)$ & $3(9.70)$ & & \\
\hline $51-75$ & $11(28.2)$ & $20(51.3)$ & $8(20.5)$ & & \\
\hline Education & $3(15)$ & $14(70)$ & $3(15)$ & $9.876(4)$ & $0.043^{*}$ \\
\hline SSLC & $0(0)$ & $11(68.8)$ & $5(31.2)$ & & \\
\hline PUC & & & \\
\hline Diploma/ \\
graduate \& above
\end{tabular}

Fig. 1.Pie diagram showing the knowledge scores of sample on food adulteration

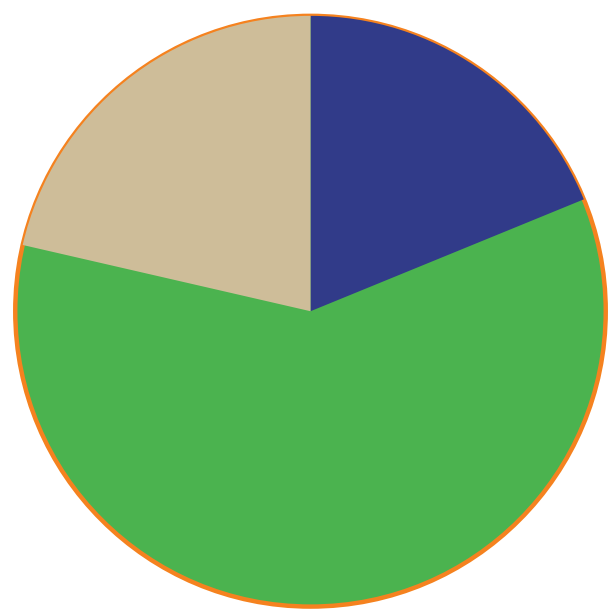

Poor Knowledge

Average knowledge

Good knowledge

\section{References}

1. Gupta N, Panchal P. Extent of awareness and food adulteration detection in selected food items purchased by home makers. Pakistan journal of nutrition 2009; 8: 660-667.

2. DTE News. Food Adulteration, Food Safety, Food Standards, Health Effects, India, Karnataka, M ysore (T) . M ay 15, 2008

3. Working of the Prevention of Food Adulteration Act, 1954 in different states /UTs,-2002(commodity wise). Available from URL:http://cbhidghs.nic.in/hia2005/14.03.htm

4. http://en.wikipedia.org/wiki/Food.

5. Beniwal A and Khetarpaul N. Knowledge of consumers regarding the nature and extent of adulteration of Indian foods. Sage publications. Nutrition and Health1999;13(3): 15360.DOI: $10.1177 / 026010609901300303$.

6. Bhatt SR, Bhatt SM , Singh Anita. Impact Analysis of Knowledge Practice for Food Safety.Pakistan Journal of Nutrition. 2010. 9 (2): 186-190. 